\title{
Design, construction and evaluation of a dual device with cellular / satellite coverage for mobile asset tracking technology transfer through
}

\section{Diseño, construcción y evaluación de un dispositivo dual con cobertura celular/satelital mediante transferencia tecnológica}

\author{
Hernán Paz-Penagos \\ $\mathrm{Ph}$. D. Education. \\ Colombian School of Engineering Julio Garavito. \\ Bogota, Colombia. \\ hernan.paz@escuelaing.edu.co \\ Marco Andrés Ortiz-Niño \\ Electronic Engineer, \\ Colombian School of Engineering Julio Garavito. \\ Bogotá, Colombia \\ marco.ortiz@escuelaing.edu.co
}

\author{
Johnny Alexander Arevalo-López \\ Electronic Engineer, \\ Colombian School of Engineering Julio Garavito. \\ Bogotá, Colombia. \\ johnny.arevalo@escuelaing.edu.co \\ Roberto Ferro-Escobar \\ Electronic Engineer, \\ Francisco José de Caldas Distrital University \\ Bogotá, Colombia \\ Ferro.roberto@gmail.com
}

\begin{abstract}
This paper presents the design, construction and evaluation of the wireless device OSP cellular and satellite coverage for localization and tracking of mobile assets in Colombia (public transport, freight, carriers, etc.). The development of this product integrates hardware, software and communications interfaces, and it is aligned with a need identified in the market by the company One Solution Position: OSP LTD. With this technology transfer is to improve in offering wireless services for mobile asset tracking using a dual cellular/satellite, versatile, economical, low-power, limited only international standards FCC and CE Mark.
\end{abstract}

Keywords- GPRS technology, satellite device, location, tracking, mobile assets.

Resumen- Este artículo presenta el diseño, construcción y evaluación de un dispositivo inalámbrico de cobertura celular y satelital para la localización y el rastreo de activos móviles en Colombia (transporte público, transporte de carga). El desarrollo de este producto integra hardware, interfaces de comunicaciones y software, y está alineado con una necesidad detectada en el mercado por la empresa One Solution Position: OSP LTDA. Con esta transferencia tecnológica se busca mejorar mediante una solución dual celular/satelital, versátil, económica, de bajo consumo y ceñida a la normatividad internacional FCC y CE Mark, la oferta de servicios inalámbricos para seguimiento de activos móviles.

Palabras clave- Activos móviles, dispositivo satelital, localización, seguimiento, tecnología GPRS.

\section{INTRODUCTION}

Colombian telecommunications is a dynamic sector (continual growing of users and new services), that offers multiple opportunities to the electronic engineering for the development of pertinent solutions from the tracking technological transfer.

In that perspective, it was identified that wireless communication market, specifically in technological solutions for tracking and following of mobile asset, offers GPRS transmission equipment with cellular coverage. In [1] explains the politics of this services in Colombia; the limitation of this kind of solutions is that information flux is maintained while antenna connection exists; however, the communication get lost in remote regions. Recently, user enterprises that possess GPRS devices, and need to guarantee the continual service, must replace their modules with dual techno-logical solutions that combine land transmission modes (GPRS) and satellite (GPS). However, most of the enterprises do not have de disposition to make new inversions due to the high costs.

In that context, Electronic Engineering program of the Colombian School of Engineering Julio Gara- 
vito (performer entity) and OSP (benefactor entity) combined efforts for the design and build of dual device with cellular/satellital coverage, for forward references OSP/Satellite device, that takes existent GPRS units (Syrus and skypatrol TT8750) and makes them compatible with a satellite device, with the purpose of guarantee to the user the localization (by GPS coordinates) and the tracking mobile asset with universal coverage, versatile, to a lower cost that other types of solutions offered in the market, with low consumption and built under international standards.

In this article, it is presented the experience of designing and building of OSP/satellite device; besides, the results of working evaluation is presented, by transmission of test data.

\section{THEORETICAL FRAMEWORK}

GPRS (Global Packet Radio Service) is a standard that shares the frequency range of the GSM network using data transmission in "clusters". This standard can be consulted in [2]. In this technology, communicative channels are shared between different users dynamically. In [3] is contained the detailed procedure of this dynamic process. The principal advantage of this technology is the possibility of having a permanent terminal plugged, checked only for the volume of data send and received, and no for the connection time as happens in the transmission by circuit commutation. All concepts, procedures and services of GSM technology can be consulted in [4].

Even when data transference rate of Syrus ${ }^{\circledR}$ y skypatrol ${ }^{\circledR}$, re-used object $(115,2 \mathrm{kbps})$, may seem like obsolete for internet navigation, it is not for the development of this research, due to the information transmission speed for needs of localization and tracking of mobile asset if low.

About the satellite device, it is a technology that works with a satellite network in low orbit that spin generally bellow $5035 \mathrm{~km}$. This information can be consulted in [5]. Its functionality goes beyond tracking and following mobile assets, they also allow data transfer in simplex and/or duplex mode with low latency and global coverage. In [6] there are detailed information of GPS services. This service is provided now by different companies such as Iridium $\AA$, Globalstar $\AA$, OrbComm $\AA$, that have their own satellite constellation LEO and of satelli- te modems Directly in [7]-[9] are the detailed information of the infrastructure of these companies.

In this days exist diverse wireless communications systems for tracking and/or control of mobile assets (vehicles, buses, etc.) of local or regional coverage by GPRS (Sony/Ericsson $\AA$, Enfora ${ }^{\circledR}$ GSM2218, Hunter Pro ${ }^{\circledR}$, Syrus ${ }^{\circledR}$ y Skypatrol $\left.{ }^{\circledR}\right)$, of national or universal coverage by satellite modems (EIT $\AA$, Iridium ${ }^{\circledR}$, Glob-alstar ${ }^{\circledR}$, Inmarsat ${ }^{\circledR}$, Orbcom $\left.{ }^{\circledR}\right)$ and duals, that combines both technologies (Matrix ${ }^{\circledR}$, Todoelectrónica ${ }^{\circledR}$, etc.). Anyway, a wide and varied offer of solutions for tracking and following of mobile assets in real time is evident and can be detailed in [10]. All of them are international and of high costs.

Referent to the current normativity for Colombia, in the telecommunication sector, its policy is to regulate guideline for services and not for technology. With that sight, it was necessary to check international normativity's founded; FCC in [11] and CE Mark in [12], with the main goal of guide the design and building of the OSP/Satellite device with international standards.

Normativity FCC refers to the correct use of frequencies and electromagnetic wave emission without interferences. For compliance of FCC normativity in the development of the OSP/Satellite device parts 15 and 25 that refer to unintentional radiations, intentional radiation and restrictions over any kind of satellite communications were followed.

With the CE MARK normativity, that regulates the production, distribution and commercialization of electronic devices for the European Union, other points are required: design and build the device that it can operate in an assigned band, give the device specifications to the client in a sheet and use minimal quantities of dangerous substances (cadmium, lead, mercury, polybromophenyls, etc.), that can affect the environment and human health. For the latter purpose there is RoHS (Restriction of Hazardous Substances) certification, also specified in [12].

\section{METHODOLODY}

Design and building of the OSP/Satellite device that allows tracking and following of mobile assets, will imply the precise knowledge of its relative location coordinates and the monitoring of va- 
riables of the mobile active that are of interest for the final user, and that will be transmitted towards a register center for control, logistic, administration and auditory of the information.

To be pertinent to the specific information needs of the user (variables to count), it was applied a questionnaire survey that had two parts and six open questions with short answers. The survey was answered for five enterprises that are users of the AVL units specified in the table I.

TABLE I

CONSULTED ENTERPRISES AND TYPE OF AVL UNITS (AUTOMATIC VEHICLE LOCATION) USED

\begin{tabular}{|c|c|}
\hline Consulted enterprise & AVL unit used \\
\hline Impel & Enfora \\
\hline Kenssey & Sky Patrol \\
\hline Rastrack & Enfora \\
\hline Roca & Enfora \\
\hline Securitas & Syrus \\
\hline
\end{tabular}

Source: OPS and ECITONICA.

In general polled people in the enterprises coincide in affirm that variables of interest for their respective enterprises are these pointed in Fig. 1.

Fig. 1. TYPE OF VARIABLES OF INTEREST FOR THE POLLED ENTERPRISES

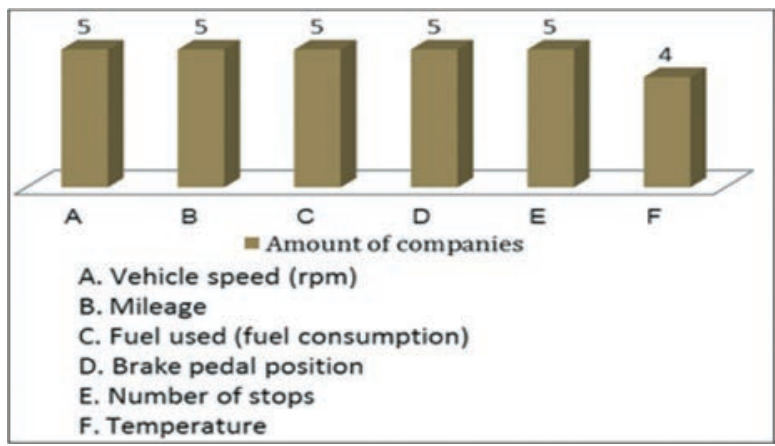

Source: ECITRONICA Group.

The OSP/Satellite device pertinent to the necessities of the user enterprises considered the development of hardware, communication interfaces and software for its performance in the operative stage that is shown in the fig. 2 .
Fig. 2. WIRELESS COMMUNICATION SYSTEMS WITH CELLULAR AND SATELLITAL COVERAGE

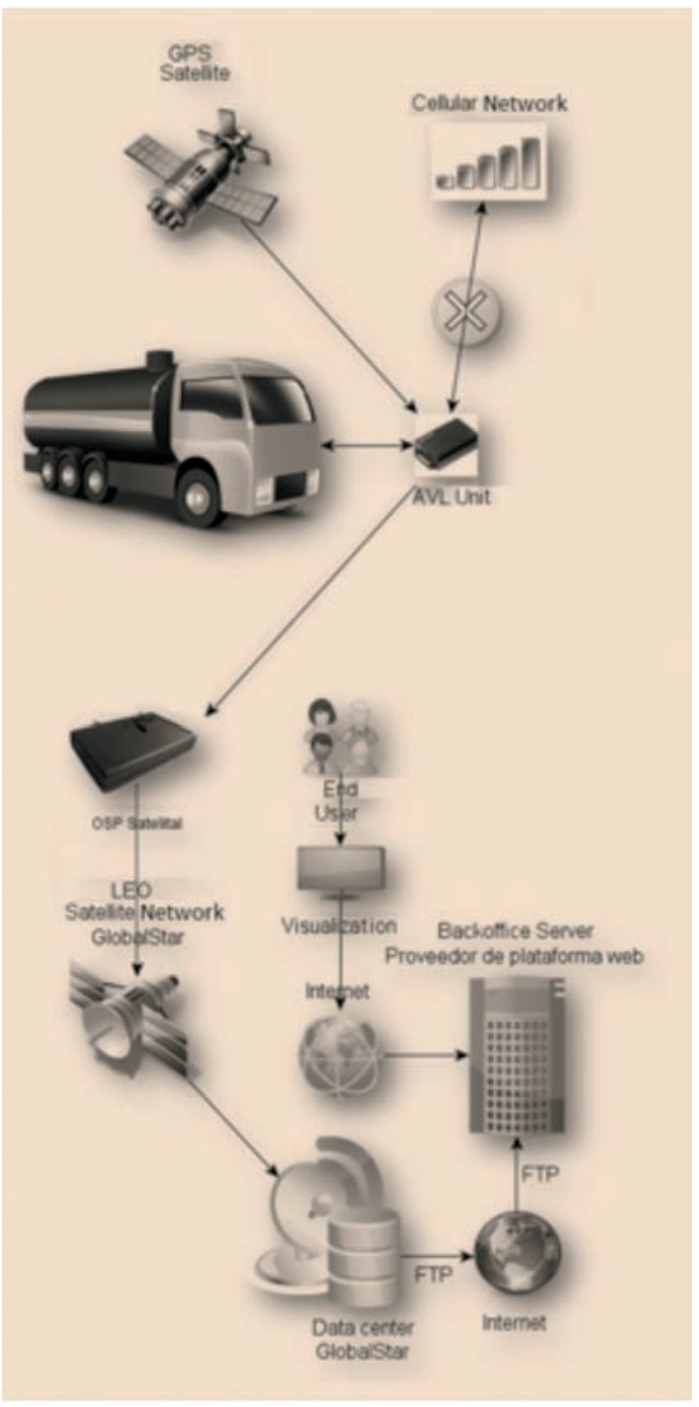

Source: ECITRONICA Group.

This electronic engineering work also had in mind the following market requirements: 1) Possibilities of universal coverage; however, it was implemented to reach national and regional coverage that comprehends Andean zone countries; 2) From the monitoring center, the offering of regular location uploads of the mobile actives; 3 ) The GPRS modem will work with low frequencies respect de $3 G$ and $4 G$ technologies, which guarantees a low battery consume. 4) The low battery consume will be guaranteed by the following strategies: STX-2 deactivation when it is not transmitting, PWM signal for LED's visualization feed and change the microcontroller to hibernation status when it is not transmitting; 5) The appro- 
ximate dimensions of the OSP/Satellite device are: $9.2 \times 6.3 \times 4.0 \mathrm{~cm}$; approximate weight: $400 \mathrm{~g}$; Satellital Antenna: $5 \mathrm{~m}$ of wire; 6 ) The OSP/Satellital broadcast RF power levels allowed, to avoid electromagnetic interferences; 7) This device will operate with GLOBALSTAR ${ }^{\circledR}$ satellital network, in low orbit to $1414 \mathrm{~km}$, Band L, $\mathrm{F}=1616.25 \mathrm{MHz}$, $\mathrm{BW}=7.5 \mathrm{MHz}$; 8) Maximum of sending information capacity: 16 messages (144 bytes), compatibility: Syrus, Skypatrol: TT8750; 9) The OSP/Satellital will be feed with a range of voltage that will oscillate between $2.7 \mathrm{~V}$ and $5.5 \mathrm{~V}$, with a Imax of $1.1 \mathrm{~A}$. In the same way, it will have a $3.7 \mathrm{~V}-1000 \mathrm{~mA} / \mathrm{h}$ lithium internal battery. Charge time: $4 \mathrm{~h}$. Reception sensibility: $-93 \mathrm{dBm}$; 10) this device will have an integrated smart Bluetooth terminal to $2.4 \mathrm{GHz}$ and transmission power from $0 \mathrm{dBm}$ to $-23 \mathrm{dBm}$.

\subsection{Hardware modeling of the OSP/satellite device}

As it is shown in Fig. 3, the design of the hardware of the OSP/Satellite device consist of internal modules, ports for external modules, Bluetooth, STX-2 satellital and microcontroller.

Fig. 3. BLOCKS DIAGRAM FOR THE OSP/SATELLITE DEVICE

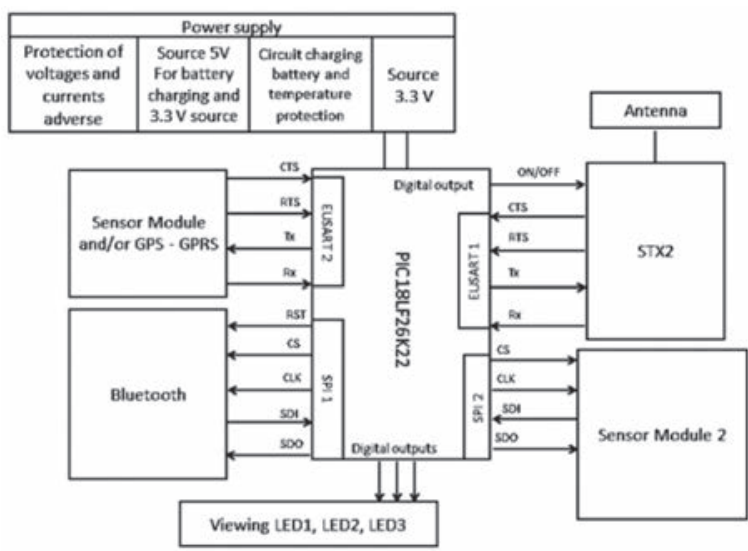

Source: ECITRONICA Group.

\subsection{Modeling of the communication interfaces}

The design of the communication interfaces with serials SPI (Serial Peripheral Interface) and asynchronous UART (Universal Asynchronous Receiver-Transmitter) for the interconnection of the circuit blocks (hardware), will allow the ensemble (OSP/Satellite device) the transmission of satellital information over the coordinates of the mobile asset and values of the electrical variables captured by the GPRS existent system (sensors module).
Internal modules are communicated with each other by inter-faces that are shown in Fig. 4. These show the way that follows the information flux.

Fig. 4. INTERFACES OF COMMUNICATION AND CIRCUIT BLOCKS THAT ARE INTERCONNECTED

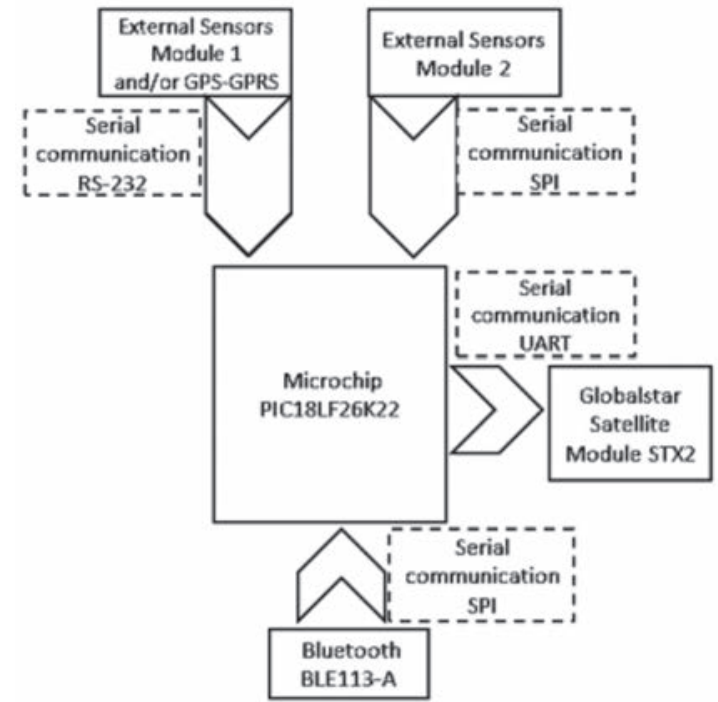

Source: ECITRONICA Group.

As shown in Fig. 5, the information captured by the sensors external module and saved in the microcontroller can also be received in a smartphone, tablet or laptop with Bluetooth communication.

Fig. 5. INTERFACES OF COMMUNICATION INVOLVED IN THE LINK BETWEEN SENSORS EXTERNAL MODULE AND A BLUETOOTH TERMINAL
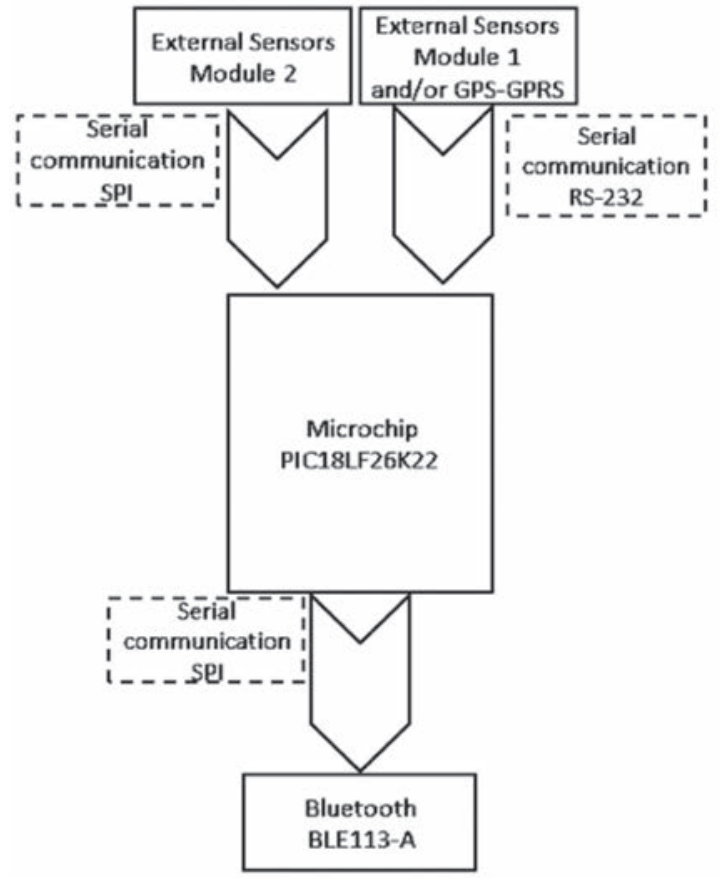

Source: ECITRONICA Group. 
The firmware was programmed in C language using PICC compiler and development interface MPLABX. The firmaware was developed with the purpose of setting the OSP/Satellite device to be versatile, to fulfill the standards and operate with lower power consumption. Programming logic that was followed for software development at reception shown in the following flowchart of Fig. 6.

Fig. 6. FLOW CHART OF THE SOFTWARE

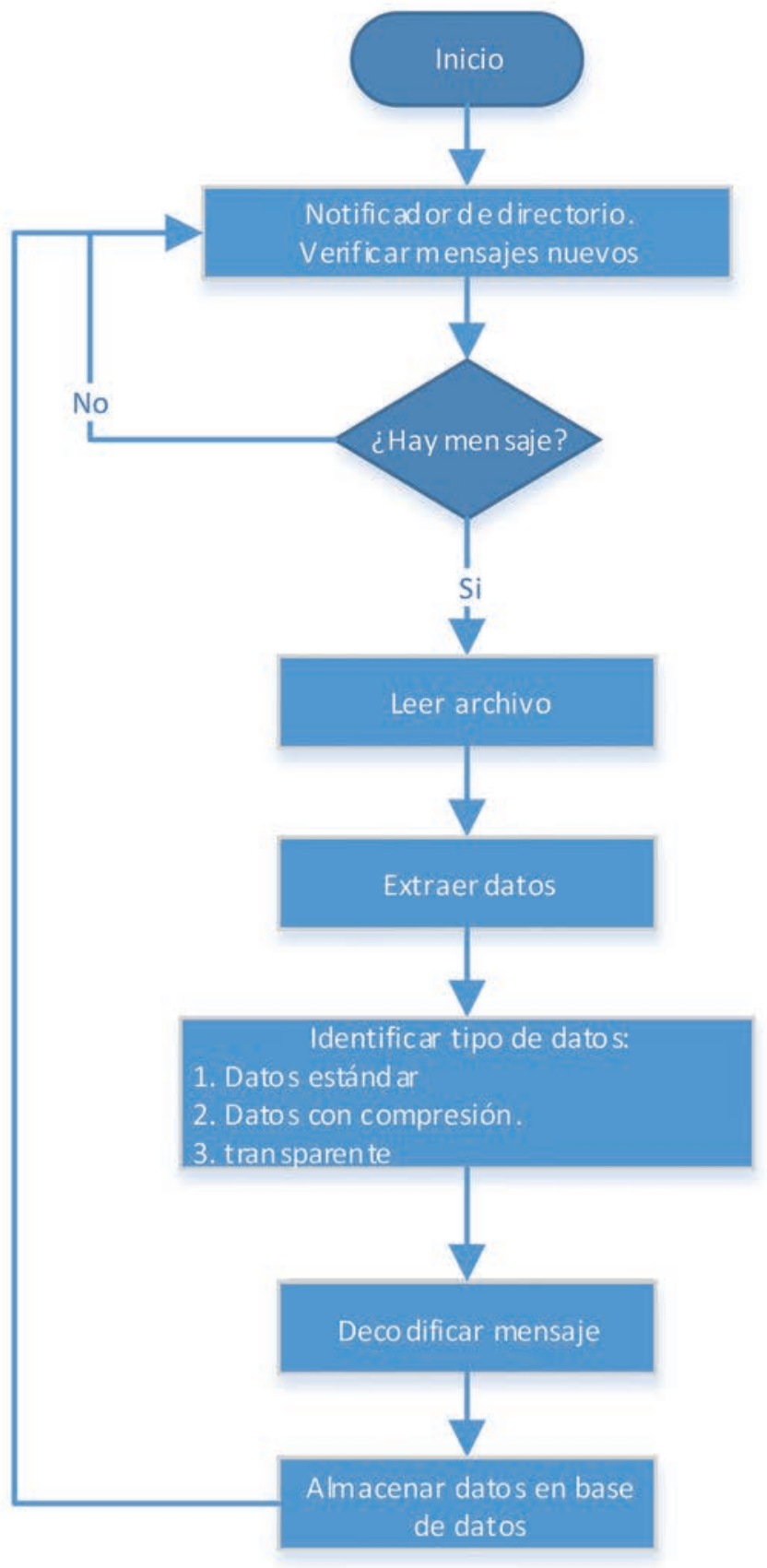

Source: ECITRONICA Group.
The reception software was developed in programming language Python that will be executing in a machine with an operative system Ubuntu 14.4 and which main goal is to detect the moment in which a satellital message is received in the server, capture the information contained in the message, decoding it and give it in an e-mail.

For the management of the socket a script was made, that initially was been executed in the server of the benefactor enterprise OSP, in order to receive satellite connection sent by the OSP/Satellite device (located in the Colombian Engineering School)

To check the working of the OSP/Satellite device the next steps were followed: 1) Install a FTP service on the server, that al-lowed the reception of XML files, that for the first test were sent from GLOBALSTAR to an e-mail, with the information required of the satellite message. 2) A script was developed which could make the following activities pat the same time:

- Get connected to an e-mail

- Make a directory event notifier that when validating the creation of new XML files in a specified route, opens them, ex-tracts the information, decoding and after sends to the development engineers' e-mail the decoding information with the XML file attached.

\section{RESULTS}

The designed and built OSP/Satellite device had the technical specifications described in the following Table II.

From the first and only test some fractions were received on the e-mail with content such as what is shown in the Fig. 7. With the basis of this information the XML file was created.

Once the XML file was created, the script automatically opens it to make the decoding.

Created file is decoding by script, which is executed in the reception server, and a new e-mail message is sent to the development engineer for information validation.

In the content of the mail it is shown the understandable information that has the following data:

- Date

- Hour

- Latitude 
TABLE II

TECHNICAL SPECIFICATIONS OF THE OSP/SATELLITE DEVICE

\begin{tabular}{|c|c|}
\hline & Dimensions \\
\hline \multirow{2}{*}{ Size } & Satellital Antenna: $8.4 \mathrm{~cm} \times 7.5 \mathrm{~cm} \times 4 \mathrm{~cm}$ \\
\hline & Device: $10.5 \mathrm{~cm} \times 9.5 \mathrm{~cm} \times 4 \mathrm{~cm}$ \\
\hline \multirow{2}{*}{ Peso } & Satellital Antenna: $\sim 180 \mathrm{~g}$ \\
\hline & Device: $~ 300 \mathrm{~g}$ \\
\hline \multicolumn{2}{|r|}{ Environmental tolerance } \\
\hline Charging temperature & $-5^{\circ} \mathrm{Ca}+55^{\circ} \mathrm{C}$ \\
\hline \multirow{2}{*}{ Operative temperature } & Satellital transmitter: from $-5^{\circ} \mathrm{C}$ to $+55^{\circ} \mathrm{C}$ \\
\hline & Antenna: from $-5^{\circ} \mathrm{C}$ to $+55^{\circ} \mathrm{C}$ \\
\hline \multirow{2}{*}{ Relative humidity } & Satellital Transmitter: $85 \%$ \\
\hline & Antenna: $85 \%$ \\
\hline Electric surrounding & IP 65, NEMA 12 \\
\hline & Electric tolerance \\
\hline Incoming voltage & $10 \mathrm{VDC}$ a $30 \mathrm{DC}$ \\
\hline \multirow{3}{*}{ Current consume } & In satellital transmission: $\min 650 \mathrm{~mA}$ \\
\hline & Max: $1 \mathrm{~A}$ \\
\hline & At inactivity : $15 \mathrm{~mA}$ \\
\hline \multirow{4}{*}{ Protection } & Voltage peak suppressor \\
\hline & Inverse polarity voltage \\
\hline & Overcurrent \\
\hline & High $\left(55^{\circ} \mathrm{C}\right)$ and low $\left(-5^{\circ} \mathrm{C}\right)$ thermic temperatures \\
\hline \multirow{2}{*}{ Coupling plugin } & Device: DB9 nut with connection to existent GPRS \\
\hline & Satellital Antenna: SMA Nut \\
\hline & Dispositive: Male connector for external module of sensors. \\
\hline Battery voltage & 3.7 VDC \\
\hline Charge current (battery) & $700 \mathrm{mAh}$ \\
\hline \multicolumn{2}{|r|}{ Satellite } \\
\hline Version & Globalstar STX-2 \\
\hline Transmission frequency & 1611.25 MHz a $1618.75 \mathrm{MHz}$ \\
\hline Transmission power & $18 \mathrm{dBm}+/-2 \mathrm{~dB}$ \\
\hline Mode & Simplex \\
\hline Antenna & Type: Patch. Connector: SMA Nut \\
\hline \multirow{4}{*}{ Compatibility } & GPS - GSM/GPRS Existents \\
\hline & Syrus DCT \\
\hline & Enfora \\
\hline & Skypatrol TT8750 \\
\hline \multirow{2}{*}{ Interfaces } & RS232. Duplex communication. Default Baud Rate: 115200. \\
\hline & SPI. Molex 4 inputs / outputs configurable. Duplex communication. Master Mode. Transmission rate until $4 \mathrm{MHz}$ \\
\hline \multicolumn{2}{|r|}{ Bluetooth } \\
\hline Version & 4.0 Bluetooth Smart \\
\hline Frequency & $2.402 \mathrm{GHz}$ to $2.480 \mathrm{GHz}$ \\
\hline Modulation & GFSK \\
\hline Transmission Power & $+0 \mathrm{dBm}$ \\
\hline Receiver sensibility & $-93 \mathrm{dBm}$ \\
\hline Reach and line of sight & 100 meters \\
\hline Mode & Duplex \\
\hline \multicolumn{2}{|r|}{ Certifications } \\
\hline Satellital & Inmarsat ISATM2M \\
\hline Regulator & FCC, CE \\
\hline \multicolumn{2}{|r|}{ Processing } \\
\hline Processor & Microchip 18If26k22 \\
\hline Flash Memory & $64 \mathrm{kB}$ \\
\hline SRAM & 3896 Bytes \\
\hline \multicolumn{2}{|r|}{ Satellital messages } \\
\hline \multirow{2}{*}{ Plot } & Message size of 9 bytes \\
\hline & Max 16 messages \\
\hline
\end{tabular}


Fig. 7. SATELLITAL MESSAGE CONTENT

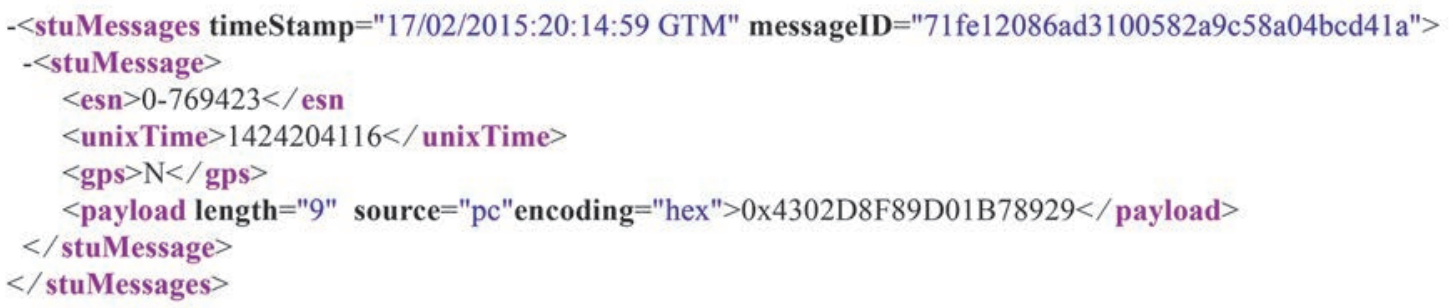

Source: ECITRONICA Group.

- Longitude

- Event

- Orientation

- Speed

- Hexadecimal representation

- Binary representation

- Google-maps link to see the coordinates in a map

Besides, the mail contains the XML file attached to verify the information.

\section{1 Data analysis}

A challenge that is presented in the design of an OSP/Satellite device is that the integrated circuit STX2, that is used in the project and is commercialized by GLOBALSTAR®, counts with a transmission mode of simplex information, without detection and errors correction over the sending of the data to the final customizer. This information can be founded in [13]; in consequence, it is not guaranteed the reliability of the transmitted data. To solve this issue techniques that allow error correction in the receptor without retransmission of the original information were applied (FEC: Forward Error Correction).

GLOBALSTAR ${ }^{\circledR}$ satellites network, that will facilitate to the OSP/Satellite device its universal coverage, presents availability between $90 \%$ and 95\%, with a delay of the communications of $20 \mu$ s, approximately.

Due to the OSP/Satellite device user is not disposed to pay more money than to the send of the message, it is necessary the compression of the information of the locate coordinates of the mobile asset and analogic entrances or digitals that inform about the driver behavior and gas consumption, (these information cannot exceed a 9 bytes message).

The protocol for the serial communication RS232 between the conventional AVL devices (commercialized in Colombia) and the OSP/Satelital, based in ASCII, generates processing consumption in the microcontroller of both devices [14], [15]. This procedure could be made in the software and so reducing the size in firm-ware.

\section{CONCLUSIONS}

The dual solution will allow the transference of data between the final user and its following asset that will be made by the use of GPRS technology for zones in Colombia that have cellular network coverage and with satellite communication modem LEO for those zones that do not have GPRS coverage.

Design of any electronic product with compliment of an international standard can be performed from two perspectives: starting of zero and guide the design process (stage by stage) with the compliment of the respective recommendation [16]; or start from the selection of the elements of the desired certification. In that case it is wished to compile the standard related to the integration and performance of the device in general.

Transmission rates of the OSP/Satellite device to the final user must be adjusted in a way that data flow between modules is appropriate, does 
not rewrite the information and neither generates unnecessary energy consumption.

\section{ACKNOWLEDGMENTS}

For the contributors of valuable comments and hosting this research, the engineers Nestor Guerrero and Juan Pablo Londoño of One Solution position LTDA.

\section{REFERENCES}

[1] Colombian Department of commerce. Infrastructure, transport and logistics. Competitive National Politics 2013-2014. vol. 1, no.1 272 pp. October 2013.

[2] M. Rahnema, "Overview of the GSM System and Protocol Architecture," IEEE Communications, vol. 31, no. 4, pp. 92- 100, April 1993.

[3] Ch, Bettstette, H Vögel and J Eberspächer. "GSM Phase 2+ General Packet Radio Service GPRS". IEEE Communications Surveys, vol. 2, no. 3, p. 67-78. May, 1999.

[4] G. Brasche and B. Walke, Concepts, Services, and Protocols of the New GSM Phase 2+ General Packet Radio Service, I E E E Communications, vol. 35, no. 8, pp. 94-104, August 1997.

[5] A Sendín. "Fundamentos de los sistemas de comunicaciones móviles". First Edition Madrid, España. 2004. McGraw-Hill. Chapter 11, Sections 1.2 and 1.3. Páginas: 479-497.

[6] M. Schenewerk. "A brief review of basic GPS orbit interpolation strategies". GPS Solutions, Vol 6, P. 265-267. November 2003
[7] GLOBALSTAR. Online http://www.wp.com/mcintosh_ page_o_stuff/globals.html. Retrieved July 13, 2014

[8] IRIDIUM. Online http://www.iridium.com. Retrieved February 13, 2014

[9] ORBCOMM. Online http://www.orbcomm.net. Retrieved June 13, 2014

[10] Y. Ojeda, \& C. Sánchez, \& E. Pérez. "Tipología de Proyectos de Carácter Científico, Tecnológico e Innovación".First edition. Bogotá Colombia. 2011. Consejo nacional de beneficios tributarios-CNBT, acuerdo 01 de 2011. pp. 21.

[11] "FCC rules". Online http://highfreqelec.summittechmedia.com/Jan05/HFE0105_Tutorial.pdf. Retrieved July 13, 2014. May. 2014

[12] CE MARK. Guidelines on the application of directive. vol. 1, no. 1 p.37. Jun. 2007.

[13] A. Goldsmith, A. "Cellular systems and infrastructureBased Wireless networks". "Wireless communications". First Edition. Stanford University: California, United States. 2005. Chapter 15. Sections 15.3-15.6. $633 \mathrm{p}$.

[14] H. Granbohm and J. Wiklund, GPRS: General Packet Radio Service, Ericsson Review, vol. 76, no. 2, pp. 8288, 1999.

[15] J. Cai and D. J. Goodman, General Packet Radio Service in GSM, IEEE Communications, vol. 35, no. 10, pp. 122-131, October 1997.

[16] CE MARK. "Guide to the R\&TTE (Radio Equipment \& Telecommunications Terminal Equipment) Directive". Vol 1, No 1. Apr. 2009 